\title{
Viewpoint
}

\section{Is there a demand among general practitioners for inner city community hospitals?}

\author{
Sally A Hull, Ian Jones
}

Community hospitals are distributed unevenly through Britain ${ }^{12}$ and have survived despite the changing attitudes of hospital planners towards them. ${ }^{34}$ An assessment of their contribution in comparison with other sources of similar care has been hampered by poor data on costs and difficulties in assessing case mix and outcomes..$^{5-7}$ Evidence suggests, however, that community hospitals are an alternative rather than an additional place of care for elderly people and that they are popular with patients. ${ }^{89}$ McCormack has shown that community hospitals need the support of professional staff as well as financial commitment if they are to provide effective, high quality services. ${ }^{10}$ We report the demand among general practitioners for inner city community hospitals in the context of rationalisation of acute services in London. The issues raised are illustrated by the results of a survey of general practitioners' views on community hospitals in Tower Hamlets.

\section{Community hospitals in inner London}

The Tomlinson report on health services in inner London supported a further contraction in the provision of acute beds. ${ }^{11}$ The report identified that use of acute services in London was $22 \%$ above the national average, but this figure did not include use of geriatric beds. As far back as 1979 the London Health Planning Consortium noted that provision of hospital services for elderly people was $16 \%$ below the national average and that acute services were used as alternative provision. ${ }^{12}$ Similar points were raised more recently by Jarman, who showed that London has a lower than average admission rate of geriatric patients. ${ }^{13}$ The acute plus geriatric rate was $5 \%$ above the national average but below the rates for comparably deprived areas outside London. This suggests that trading off a contraction in London's acute services with developments in traditional primary care will not be an adequate solution to the problem in London. Indeed, Tomlinson identified urban community hospitals as one of the ways of strengthening primary care and advocated further developments based on the model of the Lambeth Community Care Centre. ${ }^{14}$

Achieving the best quality of care depends on patients being admitted to the appropriate setting. As the acute bed pool contracts, intermediate medical care - care that does not require the technological resources of a specialist hospital but cannot be given at home - needs to be provided. This is a particular need for elderly people, who are the greatest users of hospital services. A recent study in inner London reported that $21 \%$ of requests for admission by general practitioners are met by refusal, and this was most likely if the patient was aged 75 or older. ${ }^{15}$ The general practitioners considered $16 \%$ suitable for so called low technology beds. The lack of choice of appropriate settings for admission of patients was highlighted by a survey which found that $15 \%$ of patients in an acute hospital within inner London were perceived by doctors or nurses to be inappropriately placed. ${ }^{16}$ The implication from these studies is that a greater choice of admission settings that match patients' clinical need are a necessary part of a high quality service. Community hospitals, which are an extension of primary care, and residential and nursing homes are potential ways of filling this gap.

Two experiments in inner London community hospitals exist. The Lambeth Community Care Centre opened in 1985 and a 10 year period of development fostered the emergence of shared values and a clear idea of what its role in intermediate care should be. ${ }^{14}$ Its success has called for it to be used as a role model for replication elsewhere. Chepstow Lodge, or Paddington Community Hospital, opened in 1982 and closed in 1987 because of financial pressure within the district. ${ }^{17}$ Assessment of nursing in the hospital found more than financial problems. The purpose of the unit was not clear. Although many general practitioners had potential rights to admit patients, they were not central to the development and organisation of the project. Perhaps as a consequence of this, bed occupancy was low and nurses and general practitioners failed to agree over the categories of admission and on clinical management. A simple cost comparison indicated that the patient day costs were cheaper than at any district general hospital within the district. ${ }^{18}$

The attitude of local general practitioners has been identified as an important indicator of the success or failure of such units. In 1969 Evans and McEwan studied doctors who chose not to use their local community hospital. ${ }^{19}$ Being too busy and not being interested were the commonest reasons given. In 1977 Kernick and Davies surveyed general practitioners in Glamorgan. ${ }^{20}$ Most were interested in having 
Table 1 Characteristics of general practitioners who responded to the survey. Figures are numbers (percentages)

\begin{tabular}{lcc}
\hline & $\begin{array}{c}\text { General } \\
\text { practitioners } \\
\text { who answered } \\
(n=76)\end{array}$ & $\begin{array}{c}\text { All general } \\
\text { practitioners in } \\
\text { Tower Hamlets } \\
(n=105)\end{array}$ \\
\hline Year of registration: & & \\
Before 1970 & $13(17)$ & $24(23)$ \\
$1970-9$ & $21(28)$ & $28(27)$ \\
1980 onwards & $42(55)$ & $53(50)$ \\
No of partners: & $13(17)$ & $17(16)$ \\
0 & $25(33)$ & $38(36)$ \\
2 or 3 & $38(50)$ & $50(48)$ \\
श4 & $46(61)$ & $66(63)$ \\
Sex: & $30(39)$ & $39(37)$ \\
Male & $23(30)$ & $26(25)$ \\
Female & & \\
With MRCGP & $26(34)$ & $40(38)$ \\
Geographical area: & $15(20)$ & $19(18)$ \\
E1 & $14(18)$ & $23(22)$ \\
E2 & $21(28)$ & $23(22)$ \\
E3 & &
\end{tabular}

MRCGP $=$ Membership of the Royal College of General Practitioners.

access to beds, and they found a strong relation between age and willingness, younger doctors being keener than older doctors. The available evidence therefore suggests that for a community hospital to work and provide high quality services the commitment and support of professional staff cannot be overlooked.

\section{The Tower Hamlets survey}

In 1993, as part of a project in shared commissioning, Tower Hamlets health authority and the general practitioners' forum undertook a feasibility study for an urban community hospital. This entailed a survey of all local general practitioners as part of an approval in principle planning submission. During AprilMay 1993 a questionnaire was circulated to all 105 principals whose surgery address lay within the boundaries of the London Borough of Tower Hamlets. A further questionnaire was sent to those who did not respond about four weeks later. A final telephone reminder occurred two weeks after this. The questionnaire design consisted of a series of questions followed by a checklist response format. In the analysis that follows the wording of the questions is given in the tables. When respondents had answers additional to those listed they are indicated at the bottom of the relevant tables. In addition to the questionnaire, demographic details on all practitioners were obtained from annual report data and practice leaflets available at the family health services authority.

Information on attached and visiting staff to the practices was obtained from practice managers, general practitioners, and the family

Table 2 General practitioners' priorities * for development

\begin{tabular}{lc}
\hline & $\begin{array}{c}\text { No (\%) of respondents } \\
(n=76)\end{array}$ \\
\hline Please rate in terms of importance the following areas of development & \\
for primary care over the next two or three years: & $73(96)$ \\
Improvements to general practitioners premises & $61(80)$ \\
Mental health services based with the primary health care team & $53(70)$ \\
Extended district nursing (for example, night service) & $50(66)$ \\
Practice based health promotion and screening services & $27(35)$ \\
Facilities for general practitioners to do minor surgery & $25(33)$ \\
General practitioner led community hospital &
\end{tabular}

${ }^{\star}$ Rated 1 or 2 on a five point scale in which 1 is high priority and 5 low priority. health services authority. The questionnaire results and the demographic data were entered into Epi-Info. ${ }^{21}$ The results were presented and discussed at the Tower Hamlets GP Forum as part of the consultation process with general practitioners. The results were compared with those of a pilot survey asking about interest in a community hospital which had been circulated in May 1992 to all general practitioners in Tower Hamlets (response rate $73 \%$ (75/103)). Both questionnaires were designed to gather information on the views of individual doctors rather than a collective view from practices.

Of the 105 general practitioners practising within Tower Hamlets in May 1993, 76 responded to the questionnaire, giving a response rate of $72 \%$. A comparison of responders and non-responders showed no significant differences in sociodemographic characteristics (table 1), suggesting that this was a representative sample of general practitioners.

Table 2 shows the ratings general practitioners gave for their priorities in primary care development over the next few years. The improvement to surgery premises within the district was seen as the top priority by nearly all of them. This is reinforced by the finding that $37 \%(28)$ of general practitioners rated their current surgery premises as poor or unacceptable for the delivery of primary care.

The concept of developing a community hospital was supported by $64 \%(49)$ general practitioners (table 3). The level of support within the district showed a significant increase in the year since the pilot survey. Although most general practitioners wanted access to a broad range of facilities for their patients (table 4$)$, only a third of them $(16(33 \%))$ were prepared to commit themselves in advance to offering out of hours and night cover for inpatient beds (table 5). Of those interested in the project, most were prepared to give at least 1-2 hours a week of their time to the unit (table 6). The greatest barrier to participation seemed to be lack of interest (table 7). For those who were interested in the project, however, difficulty of access, time available during the working day, and the lack. of appropriate payment became important limiting factors. The doctor's age, the size of the practice, and the use of deputising services were not associated with expressed interest in being involved.

\section{Implications for planning services}

The survey suggests considerable support for the concept of an inner city community hospital among general practitioners in Tower Hamlets. There are several possible reasons

Table 3 General practitioners' support of idea of community hospital in pilot survey (1992) and in current survey (1993). Figures are numbers (percentages) of respondents

\begin{tabular}{lcc}
\hline & $1992(n=75)$ & $1993(n=76)$ \\
\hline In support & $24(32)$ & $49(64)$ \\
Don't know & $6(8)$ & $7(9)$ \\
Not in support & $45(60)$ & $20(26)$ \\
\hline
\end{tabular}

Increase in support for idea of community hospital between 1992 and 1993, $\chi^{2}$ for difference in proportions $=16.5 ; p<0.001$. 
Table 4 Number (percentage) of general practitioners wanting different facilities

\begin{tabular}{lccc}
\hline & Yes & No & Don't know \\
\hline $\begin{array}{l}\text { What kind of care would you like provided? }(\mathbf{n}=76)^{\star}: \\
\text { Inpatient facilities }\end{array}$ & & & \\
$\quad$ Respite care & $50(66)$ & $2(3)$ & $2(3)$ \\
$\quad$ Terminal care & $40(53)$ & $6(8)$ & $7(9)$ \\
$\quad$ Low technology medical admissions & $33(43)$ & $9(12)$ & $10(13)$ \\
$\quad$ Chronic disease investigations & $25(33)$ & $12(16)$ & $11(15)$ \\
Please indicate what other services you would like to see & & & \\
delivered from a community hospital (n=76): & & & \\
Day care and other facilitest & $37(49)$ & $15(20)$ & $9(12)$ \\
$\quad$ Minor surgery & $39(51)$ & $13(17)$ & $7(9)$ \\
$\quad$ Educational centre & $36(47)$ & $9(12)$ & $18(24)$ \\
$\quad$ Out of hours centre for mobile patients & $57(75)$ & $3(4)$ & $4(5)$ \\
\hline Outpatient physiotherapy and occupational therapy & & &
\end{tabular}

* Missing values are owing to non-response.

†Other suggestions: chiropody, counselling, dental and eye care, patient resource centre, social work.

Table 5 Medical cover among 49 general practitioners who supported idea of community hospital. Figures are numbers (percentages) of respondents*

\begin{tabular}{lccc}
\hline & Yes & No & Don't know \\
\hline $\begin{array}{l}\text { Would you like access for your patients? } \\
\text { Would you be willing to provide daytime cover? }\end{array}$ & $42(86)$ & $1(2)$ & $5(10)$ \\
$\begin{array}{l}\text { Would you (or your partners) be willing to provide } \\
\text { out of hours cover for your patients? }\end{array}$ & $31(63)$ & $10(20)$ & $8(16)$ \\
\hline
\end{tabular}

${ }^{\star}$ Missing values are owing to non-response.

for the increase in support in the year. The Tomlinson report may have generated a greater awareness of the potential role of urban community hospitals, and the local project team may have increased doctors' knowledge, especially about the amount of time and expertise to be expected from participating general practitioners. A further reason for increased support may come from the continuing contraction of the acute bed supply and the difficulties experienced in admitting patients to hospital. A community hospital might be seen as a fall back position for services under pressure. It may also be seen as a more appropriate service for patients not requiring high technology care. In addition, the wording and context of the questions may have influenced the response. The first questionnaire was seeking general practitioners' views

Table 6 Number of hours general practitioners might give to community hospital. Figures are numbers (percentages) of respondents

\begin{tabular}{lcc}
\hline & $\begin{array}{c}\text { General practitioners } \\
\text { supporting project } \\
(n=49)\end{array}$ & $\begin{array}{c}\text { General practitioners } \\
\text { not in support of project, } \\
\text { or answering don't know } \\
(n=27)\end{array}$ \\
\hline Please indicate how much time you might & & \\
give in a week to such a unit: & & \\
0 & $11(22)$ & $33(81)$ \\
$<1$ hour & $9(18)$ & $1(4)$ \\
$1-2$ hours & $22(45)$ & $4(15)$ \\
$2-3$ hours & $4(8)$ & \\
$>3$ hours & $3(6)$ & \\
\hline
\end{tabular}

Table 7 Factors that might limit general practitioners' use of a community hospital. Figures are numbers (percentages) of doctors

\begin{tabular}{lccc}
\hline & $\begin{array}{c}\text { General practitioners } \\
\text { supporting project } \\
(n=49)\end{array}$ & $\begin{array}{c}\text { General practitioners } \\
\text { not in support of project } \\
(n=20)\end{array}$ & p Value* \\
\hline Please indicate the factors that would limit & & & \\
$\quad$ your use of a community hospital: & $31(63)$ & $7(35)$ & $0 \cdot 01$ \\
$\quad$ Distance from practice & $25(51)$ & $7(35)$ & $0 \cdot 01$ \\
$\quad$ Lack of sessional payment & $25(51)$ & $14(70)$ & $0 \cdot 14$ \\
$\quad$ Time available & $7(14)$ & $11(53)$ & 0.001 \\
$\quad$ Interest & & &
\end{tabular}

on the development of low technology consultant led beds as well as a community hospital, while the second questionnaire explored the option of a community hospital in detail (see appendix for details of the wording of these questions).

It remains uncertain how this expressed support would translate into involvement in a functioning unit. To be a success the project needs the good will of most local general practitioners. It is hoped that most would have contracts to use the day care facilities, while a minority would be regular users of the inpatient facilities. Countrywide an average community hospital has only 16 general practitioners with admitting rights, ${ }^{8}$ the Lambeth centre has a fairly small core of high use practices among the 48 general practitioners with contracts.

The amount of time that general practitioners say that they are prepared to spend in the unit related well to the observational study by Rickard, who estimated that general practitioners working in community hospitals in Oxford spent an average of 1 hour 47 minutes there weekly. ${ }^{6}$ Respondents were much less enthusiastic about providing cover outside normal working hours, which reflects countrywide attitudes found in the survey by the General Medical Services Committee. ${ }^{22}$ Most of the out of hours work in community hospitals, however, seems to be associated with attached accident and emergency departments, rather than with inpatients.

Translating this level of support into a successful service requires building on the lessons of Lambeth and Paddington. The Lambeth centre may have succeeded because it developed a coherent view of its role. It has placed itself firmly within primary care and has a strong commitment to multidisciplinary management. The Paddington centre seemed to have closed as much because of a lack of coherent vision as because of a desire for economy. The nursing reports reflect the attitudes of a hospital outreach service, and the service seemed not to have been built from a primary care perspective. ${ }^{18}$

Within the current turmoil of changes to health care in London it might be tempting to grasp at developments such as this, which seem to enhance primary care and reduce the impact of hospital closures. Before attempting to set up new units similar in function to the Lambeth Community Care Centre, however, the difficulties associated with an effective evaluation need to be considered. Past evaluations, such as Rickards' study of Oxford community hospitals, tried to look at cost effectiveness, others have chosen to examine overall qualitative aspects such as the internal audit done for the Lambeth Community Care Centre. ${ }^{23}$ The opportunities for evaluation that a potential inner city community hospital offers should not be lost, however turbulent the surrounding political environment. Past difficulties encountered with global assessments suggest that one way forward would be to identify specific services within the unit and compare each with comparable alternative 
provision of care. ${ }^{23}$ Although critics might suggest that this approach would lose the holistic valuation of such a unit, the benefits gained from establishing the appropriate role of such hospitals, particularly in an inner city, would be well worth the risk.

The conflicts and constraints surrounding funding need a sensitive approach. This consultation process clearly identified the priorities for general practitioners. There was a clear message from general practitioners in Tower Hamlets that the everyday work of primary care, done from premises which reflect the rising expectations of both users and providers, must come first. Funding schemes that conflict with the development of premises in inner London would jeopardise implementation of a community hospital. Similarly, adequate remuneration for working in such units must be negotiated, and the impact of financial incentives monitored closely. The General Medical Services Committee has recently reviewed such funding and notes both its inadequacy and that most general practitioners are unsure of the sources and levels of remuneration. ${ }^{24}$ The current bed fund payments, being related to bed occupancy, provide a perverse incentive for efficiency. The establishment of community trusts can be expected to generate new thinking on this topic.

\section{Conclusions}

Community hospitals broaden the choice of appropriate settings for acute patient care; there is a particular need for this for elderly people. The results of this survey suggest that the process of consultation may have led to an increased interest in a community hospital among general practitioners. Armstrong et al have highlighted the beneficial aspects of a similar consultation process in relation to asthma guidelines. ${ }^{25}$ This consultation was broad enough to identify the priorities general practitioners have for primary care development, and they clearly thought that the capital funding for a community hospital should not conflict with improvements to surgery premises. A robust attempt at evaluating the services provided within the unit should be an integral part of any development plan. Appropriate financial support to general practitioners who extend their role to work in such a unit should be negotiated and monitored. The method of consultation used in this study can be used to identify the categories of inpatient and day care services perceived to be needed in such a hospital. The greatest barrier to use remains general practitioners' interest in the scheme. Appropriate payment may improve the participation of those who are interested, but the impact of such incentive payments should be monitored.
Part of the work for this study was undertaken by SAH while studying for an MSc in public health medicine at the London School of Hygiene and Tropical Medicine. We thank Adrian Jones, project officer at East London Health Authority, who was responsible for entering data.

\section{Appendix}

QUESTION ON COMMUNITY HOSPITALS IN TWO SURVEYS

In 1992 (pilot survey) the question on community hospitals was: Would you be interested in GP access to beds where you would provide medical care in conjunction with nursing and paramedical staff, following the model of the Lambeth Community Care Centre (as described in the covering letter)?

In 1993 (current survey) the question was: Do you support the idea of a community hospital in principle (even though you may not use it)?

In both surveys the choice of answer was yes, no, or don't know.

1 Jones $\mathrm{R}$, Tucker $\mathrm{H}$. The role of community hospitals. Health Trends 1988;20:45-8.

Cavenagh AJM. Contribution of general practitioner hospitals in England and Wales. BMFु 1978;ii:34-6.

3 Ministry of Health. $A$ hospital plan for England and Wales. London: HMSO, 1962

4 Department of Health and Social Security. Hospital services, the future pattern of hospital provision in England: a consultation paper. London: DHSS, 1980.

5 Loudon ISL. The demand for hospital care. Oxford: United Oxford Hospitals, 1970.

6 Rickard JH. Cost effectiveness analysis of the Oxford community hospital programme. Oxford: Oxford Regional Health Authority, 1976.

7 Bennett AE. Evaluating the role of the community hospital. Br Med Bull 1974;30:223-7.

8 Baker JE, Goldacre M, Muir Gray JA. Community hospitals in Oxfordshire: their effect on the use of specialist inpatient in Oxfordshire: their effect on the use of specialist inpatient

9 Hull SA. Inner city community hospitals; purchasing intermediate medical care in London. London: London School mediate medical care in London. London: Lon
of Hygiene and Tropical Medicine, 1993.

10 McCormack B. The developing role of community hospitals: an essential part of a quality service. Quality in Health Care 1993;2:253-8.

11 Tomlinson B. Report of the inquiry into London's health service, medical education and research. Oct 1992.

12 London Health Planning Consortium. Acute hospital services in London. London: LHPC, 1979.

13 Jarman B. Is London overbedded? BMF 1993;306:979-82.

4 Higgs R. Example of intermediate care: the new Lambeth Community Care Centre. BMF 1985;291:1395-7.

15 Jenkins C, Bartholomew J, Gelder F, Morrell D. Arranging hospital admission for acutely ill patients: problems encountered by general practitioners. Br $\mathcal{f}$ Gen Pract encountered by

16 Victor C, Nazareth B, Hudson M, Fulop N. The inappropriate use of acute hospital beds in an inner London
district health authority. Health Trends 1993;25:94-7.

17 North NT, Hall JD. The first inner city community hospital an appraisal of the first two years of operation. London: King Edward's Hospital Fund, 1984.

18 Paddington and North Kensington District Health Authority. Community nursing report. London: King Edward's Hospital Fund, 1984

19 Evans ED, McEwan ED. Future role of the genera practitioner in the hospital service. BMF 1977;ii:1238-9.

20 Kernick DP, Davies S. Problems in the development of the community hospital concept. BMF 1977;ii:1238-9.

21 Dean AD, Dean JA, Burton JH, Dicker RC. Epi-info version 5: a word processing, database and statistic program for 5: a word processing, database and statistic program for epidemiology on microcom

22 General Medical Services Committee. Your choices for the future. $A$ survey of GP opinions. UK report. London: future. A survey of GP opinions. UK

23 Armstrong D. Evaluating the Lambeth community care scheme. 1993. A report for SETRHA London: South East Thames Regional Health Authority, 1993.

24 Holden PJP. An explanation of GP workload and remuneration in community and GP hospitals. London: General Medical Services Committee, 1993.

25 Armstrong D, Fry J, Armstrong P. General practitioners' views of clinical guidelines for the management of asthma. International fournal for Quality in Health Care 1994;6: 199-202. 